MATHEMATICA, 60 (83), $\mathrm{N}^{\circ}$ 2, 2018, pp. 177-180

\title{
NEW CHARACTERIZATION FOR AN INEQUALITY
}

\author{
SUKET KUMAR
}

\begin{abstract}
A new characterization for the Hardy inequality for the sum of two Hardy-type integral operators is obtained between suitable weighted Lebesgue spaces, for certain ranges of indices.
\end{abstract}

MSC 2010. 26D10, 26D15.

Key words. Hardy's inequality, weight function.

\section{REFERENCES}

[1] A. Kufner and L.-E. Persson, Weighted inequalities of Hardy type, World Scientific, 2003.

[2] S. Kumar, A Hardy-type inequality in two dimensions, Indag. Math.(N.S.), 20 (2009), $247-260$.

[3] L.-E. Persson and V.D. Stepanov, Weighted integral inequalities with the geometric mean operator, J. Inequal. Appl., 7 (2002), 727-746.

[4] P.A. Zharov, On a two-weight inequality. Generalization of inequalities of Hardy and Poincaré (in Russian), Trudy Mat. Inst. Steklov 194 (1992), 97-110, translation in Proc. Steklov Inst. Math., 194 (1993), 101-114.

Received April 16, 2018

Accepted May 22, 2018

\author{
NIT Hamirpur \\ Department of Mathematics \\ Himachal Pradesh \\ 177005, India \\ E-mail: kumar.suket@gmail.com
}

DOI: 10.24193/mathcluj.2018.2.09 